\title{
Optoelectronic Properties of Antimony Doped Tin Oxide Thin Films Obtained by Spray Pyrolysis
}

\author{
B. R. Flores-Hernández ${ }^{a}$, M. Morales-Luna ${ }^{b}$, C. E. Pérez García ${ }^{a}$, S. A. Mayén-Hernández \\ F. de Moure-Flores ${ }^{a}$, J. Santos-Cruz $z^{a *}$ (1) \\ ${ }^{a}$ Universidad Autónoma de Querétaro, Facultad de Química, Posgrado en Materiales-Energía, 76010, \\ Querétaro, México. \\ ${ }^{b}$ Universidad de Monterrey, Escuela de Arquitectura y Ciencias del Hábitat, Av. Ignacio Morones \\ Prieto, 66238, San Pedro Garza García, México.
}

Received: August 13, 2021; Revised: November 17, 2021; Accepted: December 08, 2021

\begin{abstract}
Antimony doped tin oxide (ATO) thin films are deposited on corning glass substrate using the spray pyrolysis technique. The experimental parameters such as distance between the substrate and source $(10-30 \mathrm{~cm})$, substrate temperature $\left(350-450^{\circ} \mathrm{C}\right)$ and atmospheres (Nitrogen and Forming gas) are varied to study their effect on the properties of ATO thin films. The ATO thin film annealed at $425^{\circ} \mathrm{C}$ exhibits the lowest electrical resistivity of $2.23 \times 10^{-2} \Omega$-cm. Besides, the film annealed in the nitrogen atmosphere showed a less resistivity value of $9.06 \times 10^{-3}(\Omega-\mathrm{cm})$ than the forming gas atmosphere. The film doped with 3 at $\%$ of Sb revealed the highest figure of merit value of $11.45 \times 10^{-2} \Omega^{-1}$. The preferential orientation is observed at the (200) diffraction plane in all the cases from the structural studies. Furthermore, the intensity of the diffraction planes decreases as the temperature increases. The average transmittance of $75 \%$ is obtained for ATO thin films.
\end{abstract}

Keywords: Transparent Conductive Oxide, ATO, Optoelectronic devices.

\section{Introduction}

Transparent conductive oxide (TCO) materials have conductive properties close to metals and also allow the electromagnetic spectrum of visible light ${ }^{1}$. The TCO materials have been used in different fields such as screens ${ }^{2}$, sensors ${ }^{3}$, transparent electronic devices, electrochromic ${ }^{4}$ and solar cells $^{5}$. TCO material possesses band gap $\geq 3 \mathrm{eV}$ and resistivity $<10^{-3} \Omega-\mathrm{cm}^{6}$. TCO could transmit a limited light close to electrical conductivity, which is relatively low compared to metals such as silver or gold 7 . The properties of these materials are contradictory in the band structure view: a transparent material is an insulator that possesses filled valence and empty conduction bands ${ }^{8}$, whereas metallic conductivity appears when the Fermi level lies within a band with a large density of states to provide high carrier concentration ${ }^{9}$. Therefore, researchers have focused on developing TCO materials as window layers and electrical contacts in photovoltaic devices ${ }^{10}$. Nowadays, TCO materials with high mobility and increased conductivity in conjunction with good transparency are extensively studied ${ }^{11}$. In the last two decades, tin-doped indium oxide (ITO) and fluorine-doped tin oxide (FTO) thin films have been essentially employed in the semiconductor industries in highly sophisticated fields of science and technology. Despite excellent optoelectronic properties, ITO and FTO suffer from instability under reducing plasma at elevated temperatures ${ }^{9,12,13}$. Furthermore, the deficiency in the supply of rare, expensive, toxic indium and fluorine for the production of ITO and FTO thin films is an environmental

*e-mail: jsantos@uaq.edu.mx concern $^{14}$. Therefore, many efforts have been made for the substitution of these materials. In TCO, the sheet resistance is considered the essential property: ITO changes from 7 to $50 \mathrm{ohms}$ per frame depending on the deposition technique and the work surface. Besides, FTO shows the sheet resistance values in the range between 15 and 150 ohms per square. However, Sb doped tin oxide (ATO) thin films demonstrate competitive sheet resistance values ${ }^{15,16}$. The ATO thin films are considered an alternative to ITO and FTO due to their excellent calorific properties ${ }^{5,17,18}$.

In this work, ATO thin films are deposited by spray pyrolysis to use as transparent electrodes ${ }^{19}$. The experimental parameters such as temperature, dopant concentration, deposition distance, and post-treatment at different atmospheres are varied to study their effect on the ATO thin films' structural, electrical, and optical properties ${ }^{20,21}$. This is the first report for the systematic investigation of ATO thin films by varying all these parameters together. Moreover, the ATO thin films demonstrated excellent electrical properties (Resistivity $\leq 10^{-3} \Omega$-cm, carrier concentration $>10^{20} \mathrm{~cm}^{-3}$ ) and high visible transparency $(>75 \%)$ which revealed their suitability in optoelectronic devices ${ }^{22-25}$.

\section{Methodology}

The corning glass substrates were cleaned with acetic acid and acetone in an ultrasonic bath. The antimony doped tin oxide film was deposited onto the corning glass substrate by spray pyrolysis technique with a thickness of $\sim 400 \mathrm{~nm}$. For the preparation of the films, a $0.7 \mathrm{M}$ solution of stannous 
II chloride and antimony chloride were dissolved in methanol with a few drops of hydrochloric acid under constant stirring for about 2 hours. The ratio between $\mathrm{Sb} / \mathrm{Sn}$ was varied from 1 to $5 \%$, and the substrate temperature was altered from 350 to $450^{\circ} \mathrm{C}$. The distance between the source and substrate was adjusted from 10 to $40 \mathrm{~cm}$. Subsequently, the films were annealed in an inert atmosphere $\left(\mathrm{N}_{2}\right)$ and a reducing atmosphere $\left(\mathrm{N}_{2}: \mathrm{H}_{2}, 95: 5\right)$.

\section{Characterization}

The structural properties were analyzed with X-ray diffraction, using the Rigaku Miniflex X-ray diffractometer. The electrical properties of the thin films were carried out using the four-probe Mitsubishi Loresta-GP equipment and the Hall effect ECOPIA 3000. SEM and EDS measurements were performed using the Hitachi TM-1000 equipment. The optical properties were evaluated using the UV-Vis, ThermoScientific S10. The surface elemental composition of the thin films was analyzed by X-ray photoelectron spectroscopy using a Thermo Fisher Scientific K-Alpha spectrometer. The resolution of the spectrometer is around $\pm 0.2 \mathrm{eV}$. Besides, an Al K $\alpha$ X-ray source with an excitation wavelength of $1487 \mathrm{eV}$ was used. For the measurements, the energy of $50 \mathrm{eV}$, a step size of $0.10 \mathrm{eV}$, and a spot size of $400 \mu \mathrm{m}$ were employed. The experiments were repeated three times under the same conditions to check their reproducibility and the standard deviation values.

\section{Results and Discussions}

\subsection{Structural analysis}

Figure 1 shows the XRD patterns of ATO films deposited by spray pyrolysis at different conditions such as a) distance, b) temperature and c) atmosphere. The diffraction planes (110), (101), (200), (211), (220), (310), (112), (301), (202), and (321) were observed at $2 \theta$ values of $26.7,34,38,52,55$, $62,65,66.2,71.6$ and 79 degrees respectively, which match with the ICSD Card $88-0287^{26}$. It is reported ${ }^{27,28}$ that the (200) plane is related to the conduction of electrons. The highest intensity of (200) plane was obtained for the film deposited with the distance between the source and substrate of $30 \mathrm{~cm}$. Figure $1 \mathrm{~b}$ ) shows the film deposited at different annealing temperatures from 350 to $450^{\circ} \mathrm{C}$ and the highest intensity of (200) plane was observed for the film annealed in a nitrogen atmosphere at $450^{\circ} \mathrm{C}$. Figure $1 \mathrm{c}$ ) shows the film annealed at $450^{\circ} \mathrm{C}$ in two different atmospheres with a distance between source and substrate of $30 \mathrm{~cm}$. The intensity of the (200) plane is associated with greater electrical conductivity. It is found that both (200) and (112) planes exhibited greater

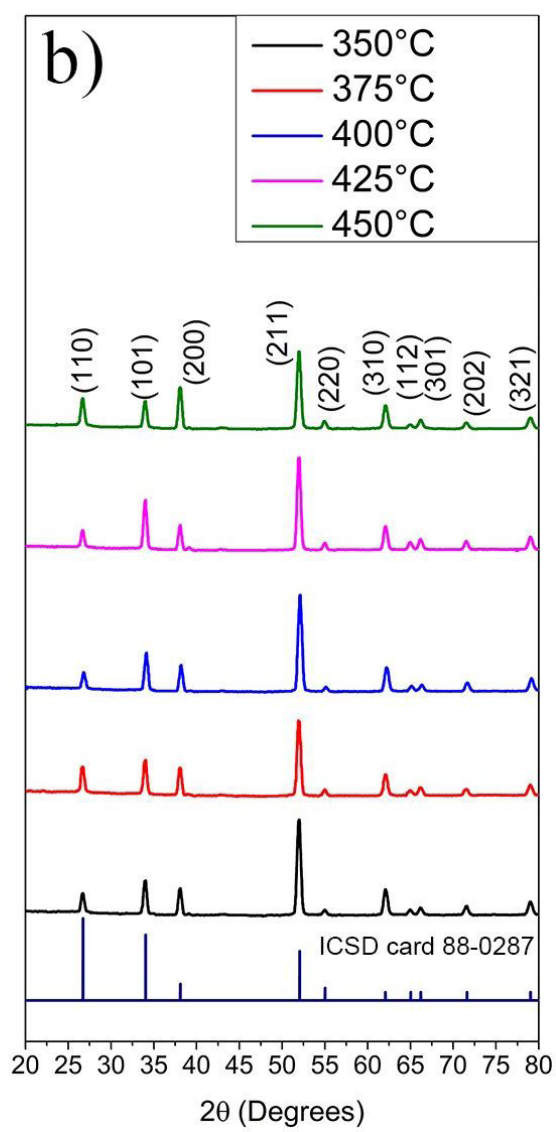

Figure 1. XRD patterns of antimony tin oxide thin films grown by spray pyrolysis at different experimental conditions a) source-substrate distance, b) temperature and c) atmosphere. 
intensity for the film annealed under nitrogen atmosphere than the samples annealed in Forming gas ${ }^{29,30}$.

The crystallite size was calculated using the WilliamsonHall equation. As shown in Table 1, a smaller crystallite size of $23 \mathrm{~nm}$ was observed for the film annealed at $425^{\circ} \mathrm{C}$ in air, which was then increased to $25.3 \mathrm{~nm}$ for $450^{\circ} \mathrm{C}$. The observed peak shift in the (200) plane indicates stress in the lattice ${ }^{31}$. This stress is related to the substitution of a larger ionic radius of tin $(162 \mathrm{pm})$ with a smaller ionic radius of antimony $(159 \mathrm{pm})^{32,33}$. The obtained stress values increased from 1 to $1.54 \times 10^{-3}$ as the annealing temperature increased between 350 and $425^{\circ} \mathrm{C}$, whereas the stress decreased to $1.54 \times 10^{-3}$ for the film annealed at $450^{\circ} \mathrm{C}$. Furthermore, the dislocation density values increased from 0.945 to $2.09 \times 10^{11}$ lin $\mathrm{cm}^{-2}$ as a function of annealing temperature. The grain size, stress and dislocation density were calculated from the Williamson-Hall equation 1.

$$
B(h k l) \operatorname{Cos} \theta=\frac{K \Delta}{D}+4 \varepsilon \operatorname{Sin} \theta
$$

Where B is FWHM of the diffraction planes, (hkl) is miller indices, $\mathrm{K}$ is the Shape factor (in this case 0.9), $\Delta$ is the wavelength of $\mathrm{CuK}$ radiation $(0.154 \mathrm{~nm}), \mathrm{D}$ is the crystallite size, $\varepsilon$ is the stress and $\theta$ is the diffraction Bragg angle.

The film annealed at $450^{\circ} \mathrm{C}$ showed a greater (200) plane intensity than the other temperatures, but a smaller crystallite

Table 1. Crystallite size, stress, and dislocation density of the ATO thin films annealed at different temperatures in the air atmosphere.

\begin{tabular}{cccc}
\hline $\begin{array}{c}\text { Annealing } \\
\text { Temp. } \\
\left({ }^{\circ} \mathrm{C}\right)\end{array}$ & $\begin{array}{c}\mathrm{D} \\
(\mathrm{nm})\end{array}$ & $\begin{array}{c}\varepsilon \\
\left(\times 10^{-3}\right)\end{array}$ & $\begin{array}{c}\delta \\
\left(\times 10^{11} \mathrm{lin} \mathrm{cm}^{-2}\right)\end{array}$ \\
\hline 350 & 33.2 & 1.06 & 0.945 \\
\hline 375 & 31.6 & 1.11 & 1.05 \\
\hline 400 & 29.3 & 1.23 & 1.11 \\
\hline 425 & 23.5 & 1.54 & 2.09 \\
\hline 450 & 25.3 & 1.34 & 1.89 \\
\hline
\end{tabular}

Table 2. Crystallite size, stress, and dislocation density of ATO thin films annealed at $425^{\circ} \mathrm{C}$ with different atmospheres.

\begin{tabular}{cccc}
\hline Atmosphere & $\begin{array}{c}\mathrm{D} \\
(\mathrm{nm})\end{array}$ & $\begin{array}{c}\varepsilon \\
\left(\times 10^{-3}\right)\end{array}$ & $\begin{array}{c}\delta \\
\left(\times 10^{11}{\left.\mathrm{lin} \mathrm{cm}^{-2}\right)}\right.\end{array}$ \\
\hline Nitrogen & 23.1 & 1.65 & 2.36 \\
\hline Forming gas & 23.4 & 1.62 & 2.45 \\
\hline
\end{tabular}

size was found at $425^{\circ} \mathrm{C}$. A smaller crystal size favors electrical properties, which could be verified with resistivity measurements ${ }^{34}$. The crystallite size, stress, and dislocation density were calculated for the film annealed at $425^{\circ} \mathrm{C}$ at different atmospheres (Figure $1 \mathrm{c}$ )). The calculated crystallite size was $23.1 \mathrm{~nm}$ and $23.4 \mathrm{~nm}$ for nitrogen and forming gas atmospheres, respectively (Table 2). Crystallite size is associated with electrical properties. Lopez-Maldonado et al. reported that increasing crystallite size decreases the grain boundaries, decreasing the energy barrier width, which influences the electrical conduction properties ${ }^{35}$. There is no significant difference in FWHM for other diffraction planes.

Figure 2 depicts surface scanning electron microscopy images of ATO thin films. Figure 2 a-c) show as-prepared ATO films, film annealed in a nitrogen and Forming gas (95\% N2: $5 \% \mathrm{H} 2)$ atmospheres at $425^{\circ} \mathrm{C}$, respectively. The average thickness of $400 \mathrm{~nm}$ was observed from the profilometer. The as-prepared film exhibited inhomogeneity grains while film annealed at different atmospheres showed a more homogeneous surface with a grain size of $40 \mathrm{~nm}$. This could be due to a greater atomic diffusion that occurred during annealing and a concentration gradient in the flow of the atmosphere ${ }^{36-38}$. The bonding between the atoms in the crystalline structure is energetically favored, resulting in a larger grain size with a lower density ${ }^{31,39}$.

Figure 3 displays the effect of the different atmospheres on the electrical properties of ATO films. The lowest resistivity was observed at $425^{\circ} \mathrm{C}$. Lower resistivities and a greater figure of merit values were obtained for the film annealed at $400^{\circ} \mathrm{C}$ in a nitrogen atmosphere compared to forming gas atmosphere. As the temperature increases, crystallinity increases, improving the electrical properties of the film. This may be due to a higher generation of $\mathrm{Sb}^{5+}$ in the $\mathrm{SnO}_{2}$ structure ${ }^{13,17,40}$. Another possible explanation is the generation of a concentration gradient of the oxygen present in the film with the environment. The mobility to the film's surface is favored, which generates an oxygen deficiency. Oxygen vacancies are associated with higher conductivity. Vacancies and doping of the film do not affect the transmission of the film, resulting in a significant figure of merit ${ }^{41}$.

Figure 4 represents the UV-Vis transmittance of ATO thin films annealed at different atmospheres. Film annealed at $375^{\circ} \mathrm{C}$ (Figure $4 \mathrm{a}$ ) with Forming gas atmosphere exhibited an average transmittance of $70 \%$, while film annealed in nitrogen showed $57 \%$ of transmittance. As shown in Figure $4 \mathrm{~b}$, film

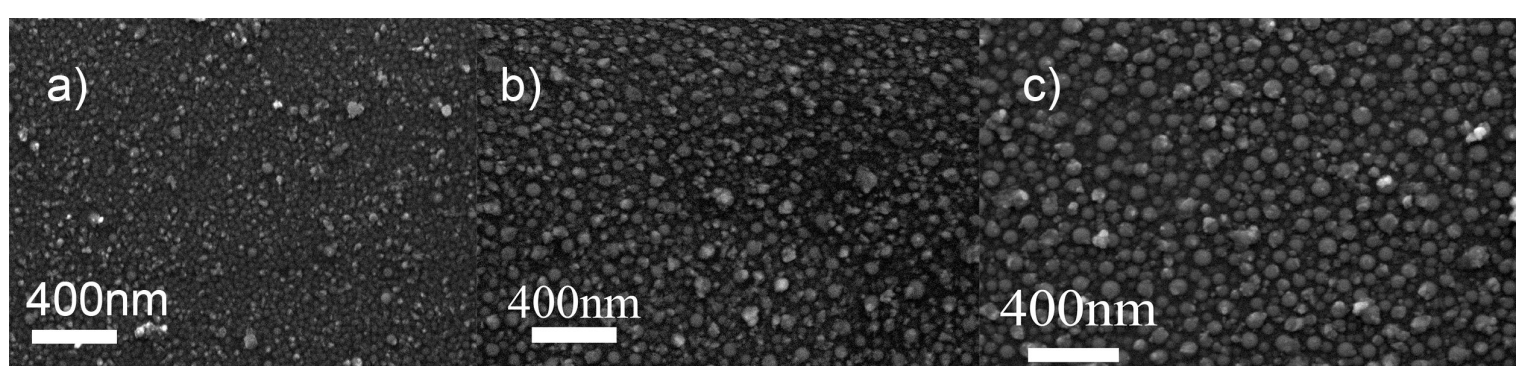

Figure 2. Scanning electron microscopy images of antimony tin oxide thin films a) as prepared, b) annealed in a nitrogen and c) Forming gas atmospheres at $425^{\circ} \mathrm{C}$, respectively. 

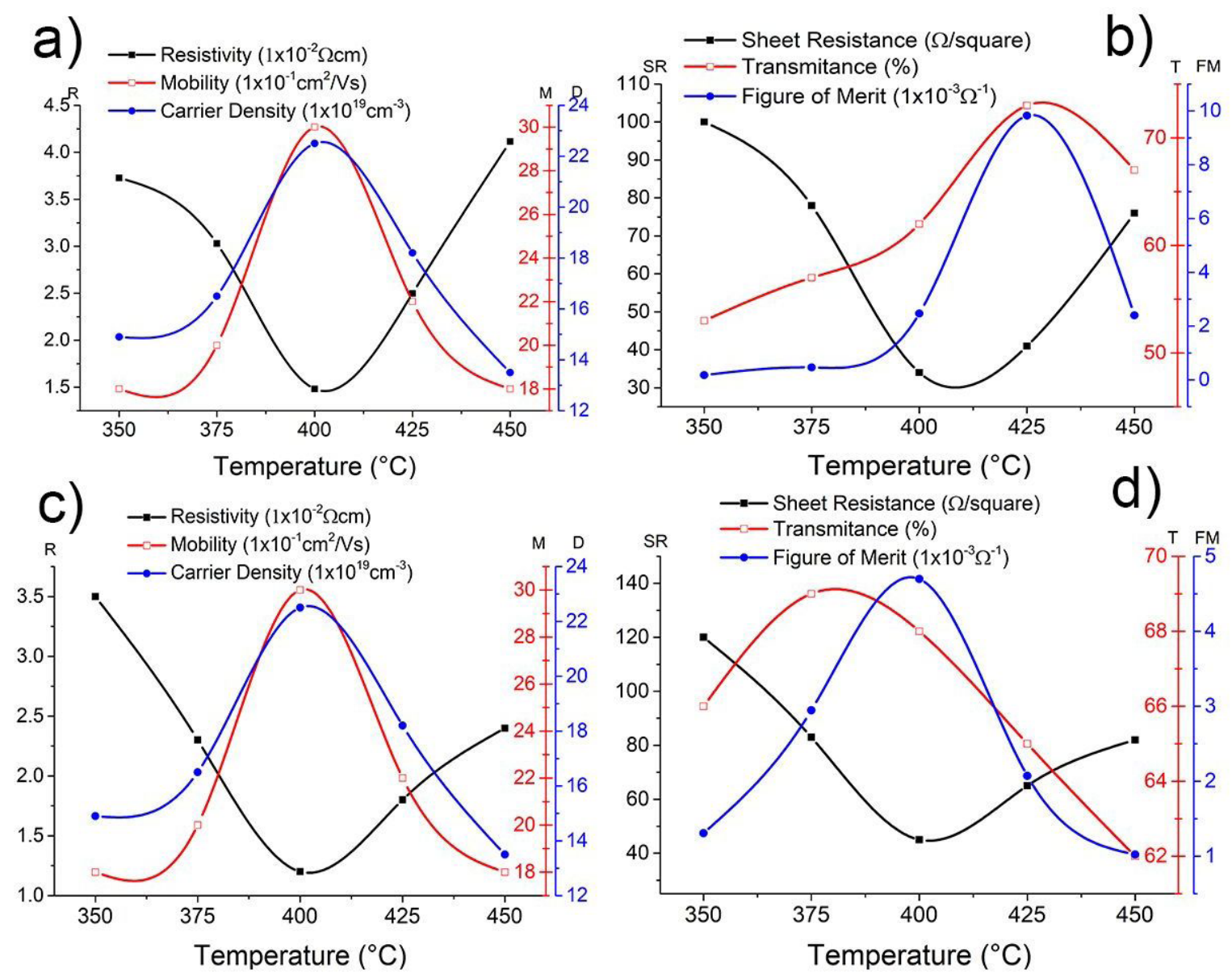

Figure 3. Variation in the electrical and optical properties of ATO thin films annealed at different temperatures $\left(350^{\circ} \mathrm{C}\right.$ to $\left.450^{\circ} \mathrm{C}\right)(\mathrm{a}, \mathrm{b})$ annealed in N2 and (c,d) Forming gas atmospheres.
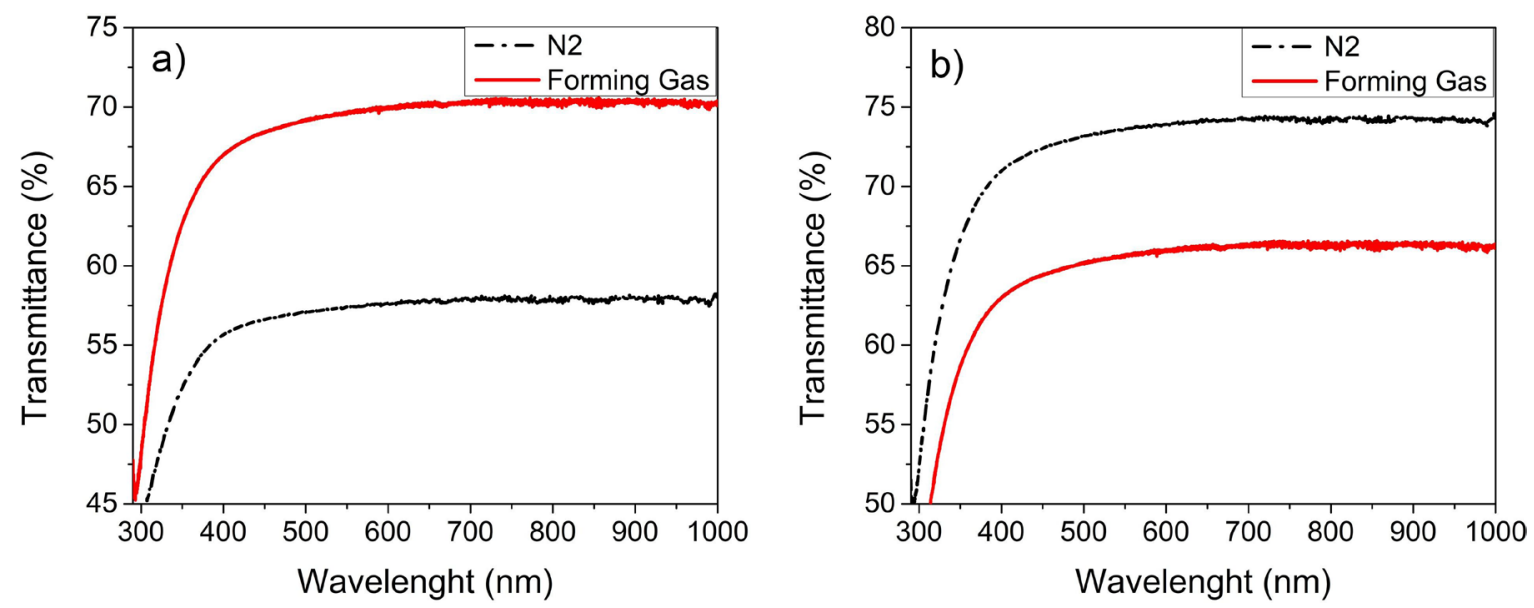

Figure 4. The transmittance of ATO thin films annealed in nitrogen and Forming gas atmospheres a) $325^{\circ} \mathrm{C}$ and b) $425^{\circ} \mathrm{C}$.

annealed at $425^{\circ} \mathrm{C}$ demonstrated the average transmittance of $73 \%$ in the range between 550 and $100 \mathrm{~nm}$, whereas $65 \%$ of transmittance was obtained in the forming gas. Therefore, the highest transmittance was attained for the film annealed at $425^{\circ} \mathrm{C}$ in a nitrogen atmosphere.
Figure 5 depicts the high-resolution XPS (HR-XPS) spectra of ATO thin films. The measurements were calibrated to the $\mathrm{C} 1 \mathrm{~s}$ peak at $284.6 \mathrm{eV}$, ascribed to the adventitious hydrocarbon deposited on the thin film surface. Also, the Shirley-type method was used to obtain the background. 

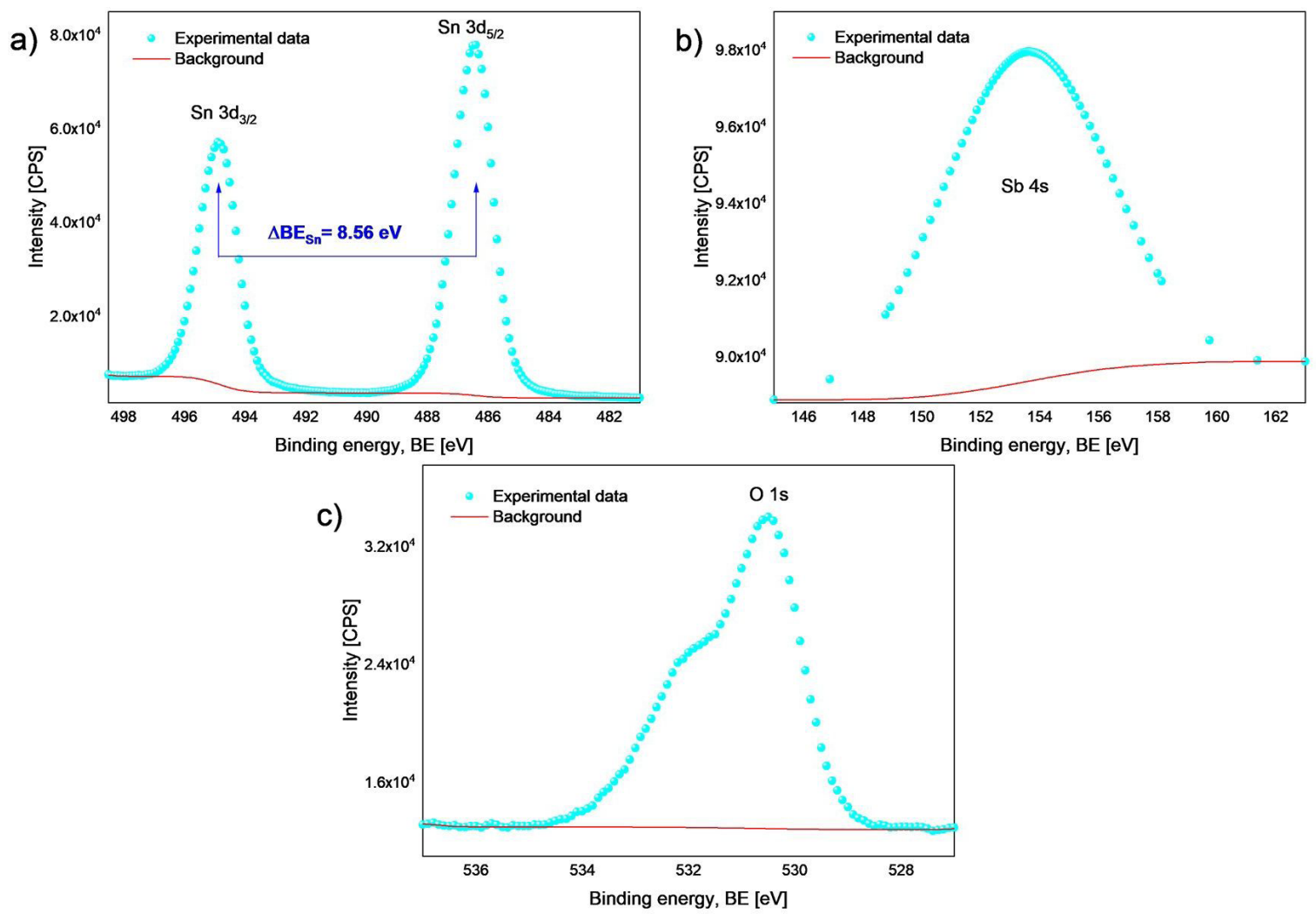

Figure 5. HR-XPS spectra of the as-prepared ATO thin films a) Sn 3d level: Sn 3d3/2 and Sn 3d5/2 levels are labelled, b) Sb 4s level and c) $\mathrm{O} 1 \mathrm{~s}$ level.

Figure 5a displays the HR-XPS spectrum of the Sn 3d level that corresponds to the spin-orbit splitting, which is a characteristic of the tin. The spectrum was deconvoluted into two doublets, associated with the $\mathrm{Sn} 3 \mathrm{~d} 3 / 2$ and $\mathrm{Sn}$ $3 \mathrm{~d} 5 / 2$ peaks, which were located at 495.13 and $486.57 \mathrm{eV}$, respectively. For the deconvolution process, the peak-topeak separation $(\triangle \mathrm{Sn} 3 \mathrm{~d})$ was obtained by the following expression: $\Delta S n 3 d=\operatorname{Sn} 3 d 3 / 2-\operatorname{Sn} 3 d 5 / 2^{42}$. The obtained value of $8.56 \mathrm{eV}$ matches well with Choi et al ${ }^{43}$. Figure $5 \mathrm{~b}$ shows the HR-XPS of the $\mathrm{Sb} 4 \mathrm{~s}$ level, which confirms the presence of antimony in the tin oxide film. The obtained peak at $153.57 \mathrm{eV}$ agrees with other reports ${ }^{44,45}$. Figure $5 \mathrm{c}$ represents the HR-XPS signal of the O 1s; the observed peak at $530.50 \mathrm{eV}$ could be associated with the oxygen of tin in the bulk as observed in other materials ${ }^{46}$.

\section{Conclusions}

ATO thin films were obtained by spray pyrolysis technique by varying the experimental parameters such as distance, temperature and atmosphere. XPS measurements confirm the presence of antimony in the film. The highest figure of merit value of $9.83 \times 10^{-2} \Omega^{-1}$ was obtained for the film annealed at $425^{\circ} \mathrm{C}$ in a nitrogen atmosphere with a distance of $30 \mathrm{~cm}$. The antimony doped tin oxide films exhibited the lowest resistivity value of $1.23 \times 10^{-2} \Omega \mathrm{cm}$ and the highest transmittance of $73 \%$.

\section{Acknowledgments}

We acknowledge the National Council of Science and Technology (CONACYT) for its financial support to the student BRFH.

\section{References}

1. Bright CI. Review of Transparent Conductive Oxides (TCO). In: Mattox D, editor. 50 Years of vacuum coating technology and the growth of the society of vacuum coaters. Tucson: Society of Vacuum Coaters; 2007. p. 10-45.

2. Minami T. Substitution of transparent conducting oxide thin films for indium tin oxide transparent electrode applications. Thin Solid Films. 2008;516(7):1314-21.

3. Panigrahi S, Martins R, Fortunato E. Progress of indium-free transparent conducting oxides, in towards oxide electronics: a roadmap. Appl Surf Sci. 2019;482:1-93.

4. Kulkarni GU, Kiruthika S, Gupta R, Rao KDM. Towards low cost materials and methods for transparent electrodes. Curr Opin Chem Eng. 2015;8:60-8.

5. Edwards PP, Porch A, Jones MO, Morgan DV, Perks DM. Basic materials physics of transparent conducting oxides. Dalton Trans. 2004;(19):2995-3000.

6. Ellmer K. Past achievements and future challenges in the development of optically transparent electrodes. Nat Photonics. 2012;6:809-17.

7. Baek JH, Seol H, Cho K, Yang H, Jeong JK. Comparative study of antimony doping effects on the performance of solutionprocessed ZIO and ZTO field-effect transistors. ACS Appl Mater Interfaces. 2017;9:10904-13. 
8. Kurz A, Brakecha K, Puetz J, Aegerter JA. Strategies for novel transparent conducting sol-gel oxide coatings. Thin Solid Films. 2006;502(1-2):212-8.

9. Dixon SC, Scanlon DO, Carmalt CJ, Parkin IP. n-Type doped transparent conducting binary oxides: an overview. J Mater Chem C Mater Opt Electron Devices. 2016;4:6946-61.

10. Wang JT, Shi XL, Liu WW, Zhong XH, Wang JN, Pyrah L, et al. Influence of preferred orientation on the electrical conductivity of fluorine-doped tin oxide films. Sci Rep. 2014;4:3679.

11. Agashe C, Hüpkes J, Schöpe G, Berginski M. Physical properties of highly oriented spray-deposited fluorine-doped tin dioxide films as transparent conductor. Sol Energy Mater Sol Cells. 2009;93(8):1256-62.

12. Mooney JB, Radding SB. Spray pyrolysis processing. Annu Rev Mater Sci. 1982;12:81-101.

13. Bisht H, Eun HT, Mehrtens A, Aegerter MA. Comparison of spray pyrolyzed FTO, ATO and ITO coatings for flat and bent glass substrates. Thin Solid Films. 1999;351(1-2):109-14.

14. Elangovan E, Ramesh K, Ramamurthi K. Studies on the structural and electrical properties of spray deposited $\mathrm{SnO} 2: \mathrm{Sb}$ thin films as a function of substrate temperature. Solid State Commun. 2004;130(8):523-7.

15. Korotcenkov G, Cho KB. Spray pyrolysis deposition of undoped $\mathrm{SnO} 2$ and $\mathrm{In} 2 \mathrm{O} 3$ films and their structural properties. Prog Cryst Growth Charact Mater. 2017;63(1):1-47.

16. Chauhan RN, Singh C, Anand RS, Kumar J. Effect of Sheet Resistance and Morphology of ITO thin films on polymer solar cell characteristics. Int J Photoenergy. 2012;2012:879261.

17. Supriyono S, Surahman H, Krisnandi Y, Gunlazuardi J. Preparation and characterization of transparent conductive $\mathrm{SnO} 2-\mathrm{F}$ thin film deposited by spray pyrolysis: relationship between loading level and some physical properties. Procedia Environ Sci. 2015;28:242-51.

18. Ellis FB, Houghton J. Chemical vapor deposition of silicon dioxide barrier layers for conductivity enhancement of tin oxide films. J Mater Res. 1989;4(4):863-72.

19. Davies BM, Pannell KH, Albright SP. Diffusion barrier of sol-gel derived silica for sprayed tin oxide film on soda-lime glass. J Mater Res. 1994;9(1):226-8.

20. Bange K, Otterman CR, Anderson O. Properties and characterization of dielectric thin films. In: Bach H, Krause D, editors. Thin films on glass. Berlin: SpringerVerlag; 2003.

21. Brinzari V, Korotcenkov G, Golovanov V, Schwank J, Lantto V, Saukko S. Morphological rank of nano-scale tin dioxide films deposited by spray pyrolysis from $\mathrm{SnCl} 45 \mathrm{H} 2 \mathrm{O}$ water solution. Thin Solid Films. 2002;408(1-2):51-8.

22. Yadav AA. Influence of film thickness on structural, optical, and electrical properties of spray deposited antimony doped SnO2 thin films. Thin Solid Films. 2015;591:18-24.

23. Consonni V, Rey G, Roussel H, Doisneau B, Blanquet E, Bellet D. Preferential orientation of fluorine-doped $\mathrm{SnO} 2$ thin films: the effects of growth temperature. Acta Mater. 2013;61(1):2231.

24. Maldonado KLL, Presa P, Rubia MA, Crespo P, Frutos J, Hernando A, et al. Effects of grain boundary width and crystallite size on conductivity and magnetic properties of magnetite nanoparticles. J Nanopart Res. 2014;16:2482.

25. Goebbert C, Nonninger R, Aegerter MA, Schmidt H. Wet chemical deposition of ATO and ITO coatings using crystalline nanoparticles redispersable in solutions. Thin Solid Films. 2009;351(1-2):79-84.

26. Kumar M, Kumar A, Abhyankar AC. Influence of texture coefficient on surface morphology and sensing properties of W-doped nanocrystalline tin oxide thin films. ACS Appl Mater Interfaces. 2015;7:3571-80.

27. Korotcenkov G, Cornet A, Rossinyol E, Arbiol J, Brinzari V, Blinov Y. Faceting characterization of tin dioxide nanocrystals deposited by spray pyrolysis from stannic chloride water solution. Thin Solid Films. 2005;471(1-2):310-9.

28. Murakami K, Nakajima K, Kaneko S. Initial growth of $\mathrm{SnO} 2$ thin film on the glass substrate deposited by the spray pyrolysis technique. Thin Solid Films. 2007;515(24):8632-6.

29. Thanachayanont C, Yordsri V, Boothroyd C. Microstructural investigation and $\mathrm{SnO}$ nanodefects in spray-pyrolyzed $\mathrm{SnO} 2$ thin films. Mater Lett. 2011;65(17-18):2610-3.

30. Guzman G, Dahmani B, Puetz J, Aegerter MA. Transparent conducting sol-gel ATO coatings for display applications by an improved dip coating technique. Thin Solid Films. 2006;502(1-2):281-5.

31. Gordillo G, Moreno LC, de la Cruz W, Teheran P. Preparation and characterization of $\mathrm{SnO} 2$ thin films deposited by spray pyrolysis from $\mathrm{SnC} 12$ and $\mathrm{SnC} 14$ precursors. Thin Solid Films. 1994;252(1):61-6.

32. Ganose AM, Scanlon DO. Band gap and work function tailoring of $\mathrm{SnO} 2$ for improved transparent conducting ability in photovoltaics. J Mater Chem C Mater Opt Electron Devices. 2016;4:1467-75.

33. Gürakar S, Serin T, Serin N. Studies on optical properties of antimony doped SnO2 films. Appl Surf Sci. 2015;352:16-22.

34. Martinez-Gazoni RF, Allen MW, Reeves RJ. Conductivity and transparency limits of $\mathrm{Sb}$-doped $\mathrm{SnO} 2$ grown by molecular beam epitaxy. Phys Rev B. 2018;98:155308.

35. Liu L, Kawaharamura T, Dang GT, Pradeep EKP, Sato S, Uchida T, et al. Study on fabrication of conductive antimony doped tin oxide thin films ( $\mathrm{SnOx}: \mathrm{Sb}$ ) by 3rd generation mist chemical vapor deposition. Jpn J Appl Phys. 2019;58:025502.

36. Zhou W, Liu Y, Yang Y, Wu P. Band gap engineering of $\mathrm{SnO} 2$ by epitaxial strain: experimental and theoretical investigations. J Phys Chem C. 2014;118(12):6448-53.

37. Rockenberger J, zum Felde U, Tischer M, Tröger L, Haase $\mathrm{H}$, Weller H. Near edge X-ray absorption fine structure measurements (XANES) and extended X-ray absorption fine structure measurements (EXAFS) of the valence state and coordination of antimony in doped nanocrystalline $\mathrm{SnO} 2$. J Chem Phys. 2000;112(9):4296-304.

38. Abendroth T, Schumma B, Alajlan SA, Almogbel M, Mäder G, Härtel P, et al. Optical and thermal properties of transparent infrared blocking antimony doped tin oxide thin films. Thin Solid Films. 2017;624:152-9.

39. Kílíç Ç, Zunger A. "Origins of coexistence of conductivity and transparency in SnO2.”. Phys Rev Lett. 2002;88:095501.

40. Batzill M, Diebold U. The surface and materials science of tin oxide. Surf Sci. 2005;79(2-4):47-154.

41. Mao W, Xiong B, Liu Y, He C. Correlation between defects and conductivity of Sb-doped tin oxide thin films. Appl Phys Lett. 2013;103:031915.

42. Ponja SD, Williamson BAD, Sathasivam S, Scanlon DO, Parkin IP, Carmalt CJ. Enhanced electrical properties of antimony doped tin oxide thin films deposited via aerosol assisted chemical vapour deposition. J Mater Chem C Mater Opt Electron Devices. 2018;6:7257-66.

43. Hofmann AI, Cloutet E, Hadziioannou G. Materials for transparent electrodes: from metal oxides to organic alternatives. Adv Electron Mater. 2018;4(10):1700412.

44. Morales-Luna M, Arvizu MA, Pérez-González M, Tomas SA. Effect of a CdSe layer on the thermo- and photochromic properties of $\mathrm{MoO} 3$ thin films deposited by physical vapor deposition. J Phys Chem C. 2019;123:17083-91.

45. Choi W, Jung H, Koh S. Chemical shifts and optical properties of tin oxide films grown by a reactive ion assisted deposition. J Vac Sci Technol A. 1996;14(2):359.

46. Nyholm R, Mårtensson N. Core level binding energies for the elements Zr-Te $(2=40-52)$. J Phys C Solid State Phys. 1980;13(11):L279-84. 